Canadian Journal of Family and Youth, 4(1), 2012, pp 1-27

ISSN 1718-9748 (C) University of Alberta

http://ejournals.library.ualberta.ca/index/php/cjfy

\title{
The "Parentification" Phenomenon as Applied to Adolescents Living Through Parental Military Deployments ${ }^{1}$
}

Deborah Harrison

Patrizia Albanese

\begin{abstract}
Many children and adolescents care for their family members in some form during their childhoods, but some take on adult roles and responsibilities beyond what is considered to be developmentally appropriate - a situation known in academic and clinical literature as parentification. Much of the literature on parentification comes from the disciplines of psychology and social work, and focuses on what are perceived to be "normal" or "abnormal" child development trajectories. The psychological literature mostly stresses the negative developmental processes that result from youth being prematurely and/or inappropriately exposed to adult roles and responsibilities. In this paper, we consider the impact of parental deployments on the lives of adolescents growing up in military families on/near a large army base in Canada. We use data from 61 semi-structured interviews conducted in 2009/10 - part of a larger mixed methods research project — to assess the adolescents' experiences of parental deployments in light of the concept of parentification. We depart from previous literature by taking a sociological approach, which shows that while adolescents take on more adult roles during parental deployments, the impact of this situation upon them varies according to their gender, their relationship with their undeployed parent, and their perception of the support they receive from their school. For the most part, adolescents whose parents are deployed experience significant quality of life losses. However, this is not true for every adolescent, and the impact of each loss depends upon the social context in which it occurs.
\end{abstract}

Deborah Harrison is Professor (retired) and Adjunct Professor of Sociology at the University of New Brunswick, and Professor (Status Only) of Sociology and Equity Studies in Education at OISEUT. She has been researching Canadian military family issues since 1990. Her books include No Life Like It: Military Wives in Canada (co-authored with Lucie Laliberté; Toronto: James Lorimer, 1994) and The First Casualty: Violence Against Women in Canadian Military Communities (with seven collaborators; Toronto: James Lorimer, 2002).

Patrizia Albanese is an Associate Professor and interim chair of the Department of Criminal Justice and Criminology at Ryerson University. Her research focuses on the impact of major social and political change on the lives of children, youth and families. Her most recent books include Youth and Society: Exploring the Social Dynamics of Youth Experience (Can. adaptation of White and Wyn; Toronto: Oxford University Press, 2011); Child Poverty in Canada (Toronto: Oxford University Press, 2010); Children in Canada Today (Toronto: Oxford University Press, 2009)

${ }^{1}$ An earlier version of this paper was presented at the Canadian Military and Veteran Health Research Forum, Kingston Ontario, November 2011. We wish to acknowledge the assistance of: the Social Sciences and Humanities Research Council of Canada Standard Research Grants Program (award \# 410-2008-0176), the provincial school district in which Armyville High School is situated, Marilyn Ball, Rachel Berman, Peggy Blackwell, Sharon Crabb, Angela Deveau, Danielle Kwan-Lafond, Lucie Laliberte, Carol MacDonald, Margaret Malone, David McTimoney, Mary Mesheau, the late Christine Newburn-Cook, Judee Onyskiw, Jennifer Phillips, Suzanne Reid, Larry Richardson, Karen Robson, Beatriz Sainz, Chris Sanders, Riley Veldhuizen, Sandra Rollings-Magnusson, the anonymous reviewers and, most of all, the adolescents we interviewed. We are also grateful to Fred Arensberg, David McTimoney, and Mary Mesheau for their comments on an earlier draft. 


\section{Introduction}

Many children and adolescents care for their family members in some form during their childhoods, but some take on adult roles and responsibilities beyond what is considered to be developmentally appropriate - a situation known in academic and clinical literature as parentification. Earley and Cushway (2002) have reviewed the history of the use of the term and reveal that the "parental child" was first used by Minuchin et al. (1967) to refer to children who assume parental responsibility in their families as a result of economic or social conditions. Following that, Broszormenyi-Nagy and Spark (1973) defined "parentification" as the expectation from a parent or parental figure that a child will fulfill a parental role within the family.

Parentification is widely understood as an interactional pattern within families in which children or adolescents are assigned roles and responsibilities that are typically considered the responsibility of adults, but which parents have relinquished. Parentified children are then expected to fulfill caretaking roles, which include the care of younger siblings, and providing comfort, advice, or protection to family members (Earley \& Cushway, 2002). Hooper (2007) notes that some researchers have distinguished among different types of parentification. For example, some have used the term instrumental parentification to refer to children taking on an unreasonable number of instrumental tasks, such as household chores and food preparation. In contrast, emotional parentification involves catering to the emotional needs of parents or siblings, or acting as the peacemaker in the family.

While some researchers note that parentification may result in the development of desirable attributes, such as resourcefulness (Ungar, Theron \& Didkowsky, 2011), much of the literature stresses the adverse effects of childhood parentification, including internalized emotional distress, externalizing problem behaviour, and interpersonal struggles (Earley \& Cushway, 2002). It is not surprising, then, that much of the literature on parentification comes from the disciplines of 
psychology and social work, and focuses on what are perceived to be "normal" or "abnormal" child development trajectories. The "negative" effects in part have to do with the original causes of the parentification. For example, parentification has been discussed in literature on parental addictions (Kelley et al., 2007), parental depression (Woolgar \& Murray, 2010), divorce (Barnett \& Parker, 1998), and child maltreatment and abuse (Fitzgerald et al., 2008). None of the literature has investigated potential connections between parentification and parental military deployments.

\section{A Sociological Perspective on Parentification}

We depart from previous literature by taking a sociological approach. This approach stresses external factors and social conditions that impact on the causes and consequences of parentification. Using this approach, we will show that while adolescents take on more adult roles during parental military deployments, the effect of this situation upon them varies according to their gender, the quality of their relationship with their undeployed parents, and their assessments of the support they receive from their school. A sociological approach challenges linear explanations, and assumes more complexity and variability of outcomes, depending on social conditions.

\section{Parentification and Military Deployments}

Canada has experienced a recent sharp increase in the frequency and danger of military deployments. During the first 12 years of the post-Cold War period (1989-2001), Canadian Forces (CF) members were deployed on 65 missions worldwide, compared with a mere 25 peacekeeping missions during the preceding 40 years [1948-1989] (Department of National Defence Canada, 2000). The CF's recent change in focus from peacetime to wartime deployments has significantly altered the lives of affected CF members and their families.

Theory and research on parenting and temporary parental absence suggest that mothers' resources, relationships, health, and difficulties (e.g., work-family conflict) influence how children cope with and adjust to their fathers' absences (Andres \& Moelker, 2011). Research on deployments 
and parent-child relationships that was carried out prior to $9 / 11$ indeed mainly focused on how mothers' parenting effectiveness during fathers' deployments was undermined by their own stress (e.g., Kelley, 1994; Medway et al., 1995). An exception was Mary Edwards Wertsch's childfocused book, Military Brats: Legacies of Childhood Inside the Fortress (1991). According to Wertsch's analysis of her interviews with 80 adult children of U.S. military members, these children had not been permitted to be children while their fathers had been deployed. Instead, they had been ordered to exhibit a stoical demeanour which, over the long term, had disrupted the honesty of their family communication and caused them to become alienated from their own emotions.

Much post-9/11 research on parent-child relationships during deployments has also focused on the child. For example, the 107 military adolescents with whom Huebner et al. (2007) conducted focus groups reported taking on significant additional responsibilities at home during deployments, providing caregiving to their undeployed parents and younger siblings, relinquishing their participation in extracurricular activities, "acting out," and suffering from depression and anxiety. The findings of Mmari et al. (2009), who conducted focus groups with adolescents, parents, and school personnel, were similar. A significant source of additional anxiety for the adolescents in Mmari et al.'s study was the high stress level of their undeployed parents (usually their mothers), who tended to become physically sick during deployments and/or excessively emotional and angry. On the positive side, these adolescents felt proud of their accomplishments; on the negative side, they felt overburdened. According to the school personnel who participated in focus groups conducted by Anita Chandra and colleagues (2010), children of deployed military members experienced troubling difficulties at school that were caused by their uncertainty about the length of the deployment, the increased stress they experienced at home, and the mental health issues they perceived to be affecting their undeployed parents. The school personnel noted with concern that these students were being expected to co-parent younger siblings, become emotional partners to their 
The "Parentification" Phenomenon

undeployed parents, and skip school in order to provide their undeployed parents with companionship. The students were relying on their schools for significant emotional support.

\section{Parentification and Gender}

For the most part, the literature on parentification treats the parentified child as gender neutral. Very few studies consider even possible gender differences in the experience of, or in outcomes related to, parentification. An exception is Mayseless's and Scharf's (2009) study of Israeli adolescent girls, which theorized that girls are more likely than boys to experience inadequate parent-child boundaries, as a result of gender-specific expectations that encourage them to believe that nurturing responsibilities are primarily theirs. The researchers followed 120 young women in their transition from high school to military service, and found that the parentified among them showed lower levels of functional independence than their peers.

\section{Perceptions of Schools' Ability to Nurture Parentified Children}

Since geographically mobile military youth tend to be constrained in their abilities to establish strong affiliations in their local communities, schools often assume heightened importance in their lives. While some literature focuses on parentified children's maladjustment in school (see Woolgar \& Murray, 2010), there is little research on the role schools can play in assisting parentified children. With the exception of the above-cited study by Chandra et al. (2010), we have found no literature on parentified military children's perception of the role schools could potentially play in assisting them to cope with their daily challenges. 


\section{Methodology}

This paper uses data from a large mixed methods study of adolescents from CF families. ${ }^{2}$ In 2009 10, we conducted two hour semi-structured interviews with $61 \mathrm{CF}$ adolescents, selected from the 1066 (of the circa 1200 enrolled) Armyville High School (AHS) students who, in 2008, had filled out a survey for our research team. Most of the survey had replicated parts of the National Longitudinal Survey of Children and Youth (NLSCY), and had compared CF and civilian youth on measures of psychological wellbeing, family functioning, attitudes toward school, and peer relationships. $^{3}$

Armyville is a "company town" which has been dominated by the presence of a large army base for several decades, and whose residents are primarily white Anglo Saxons. The ratio of CF to civilian adolescents attending AHS was approximately 50:50 in 2008/09. The school district in which AHS is located prides itself on its proactive stance towards supporting the children of $\mathrm{CF}$ members deployed to Afghanistan since 2002, and it has supplied each of its schools with a large binder of information about how parental deployments affect children's moods and progress in school.

We recruited the 61 interview participants by inviting students who had participated in the survey to volunteer by filling out contact sheets attached to their surveys. From this pool we constructed a sample consisting of 15 "CF adolescents" from each grade (16 from Grade Nine), with gender divisions reflecting our volunteer pool demographics, and an attempt to include youth with

\footnotetext{
${ }^{2}$ We defined a "CF adolescent" as a youth who had at least one parent or step-parent who either: (a) was a regular or reservist CF member; or (b) took his/her release from the regular or reserve CF during the previous five years and had been a member for at least four years prior to release. We defined a "civilian" as a youth who had no parents or step-parents who had ever belonged to the CF.

${ }^{3}$ The NLSCY is a national study of the development and wellbeing of Canadian children that began in 1994 to collect information on child development and wellbeing, and has been following its initial cohort of over 22,000 children (0-11 years) every two years (Statistics Canada, 1997). Children from military families have been excluded from this study. Our national comparison group was the CF AHS students' nation-wide age-appropriate peers who had participated in the NLSCY during the 7th (2006-07) cycle.
} 
parents representing all ranks, and both the regular and reserve forces. Since the interviews were carried out a year following the survey, these students were by then in Grades Ten, Eleven, Twelve, and recently graduated. We interviewed 35 girls and 26 boys who, among them, had 69 parents who were current or recently retired CF members. Seven (10 percent) of the 69 parents were present or former commissioned officers (captains or above); the remaining 62 (90 percent) were present or former noncommissioned members [NCMs] (e.g., warrant officers, sergeants, or corporals). This ratio varied from the 20:80 ratio of officers to NCMs that currently exists in the CF (Treasury Board of Canada, 2007). All 69 parents were present or former army members, except for three from the air element and one from the navy. None of the parents had ever been career members of the reserves.

About two thirds (42 of 61) of the participants had experienced one or more recent major parental deployments. ${ }^{4}$ Of these forty-two, 25 (or 60\%) had experienced one or more parental deployments to Afghanistan. Fifteen (or 36\%) participants had experienced recent parental deployments to Bosnia; fifteen (36\%) had experienced other recent overseas parental deployments; ten $(16 \%)$ had experienced a recent imposed restriction posting (parent was elsewhere in Canada, unaccompanied by family, usually for a year); five (12\%) had experienced parents away for several months on basic training; four $(9.5 \%)$ had had parents deployed to Haiti; two $(4.7 \%)$ had had parents deployed to the former Yugoslavia; and the parents of two participants (4.7\%) had been deployed on ships. From the numbers, it is evident that some participants had experienced multiple parental deployments during the previous few years.

The interviews covered topics unique to military life and not addressed in the survey, including relocations, deployments, deployment-related injuries (such as post-traumatic stress

\footnotetext{
${ }^{4}$ We defined "major deployment" as overseas, unaccompanied posting, basic training, or instructing courses in other provinces at least 50 percent of the time.
} 
disorder [PTSD]), family functioning, the participants' perceptions of the impact of military life stressors on their families and lives, their perceptions of how they and their families had been supported by the school and the local Military Family Resource Centre, and their perceptions of their own resilience. We asked every participant who had experienced a recent parental deployment: How did your life change during the deployment?

How did the deployment affect your parent who went away? your other parent? your parents' relationship?

What was the hardest part of this deployment for you?

What was the best part of this deployment for you (if any)? (probing for reflections on resilience and self-esteem)

How (if at all) did AHS [the school] help you adjust to the deployment?

Generally, how good a job does AHS do supporting students whose parents are deployed?

After the interviews had been transcribed, we organized the responses to our open-ended questions thematically, via an inductive process of generating categories from data, which resembled (but was not synonymous with) grounded theory methodology (Strauss \& Corbin, 1990; Charmaz, 2004). We developed initial open codes; in our second stage of coding, we further developed the open codes with the strongest evidence. In our (final) axial coding stage, we created links among the open codes.

\section{Interview Findings}

\section{(a) Parentification and Gender}

Participants of both genders carried out extra chores during deployments, and provided instrumental and emotional support to the parent and siblings who remained at home. However, the quantity and quality of the work carried out was different for boys and girls. The table below indicates the numbers of boys and girls who discussed doing extra domestic chores during a major deployment, 
categorized as care for younger siblings, indoor and outdoor chores, and caretaking emotional work (e.g., preventing conflicts or providing emotional support to siblings and the remaining parent). For each participant, as many of these categories were noted as applied. From the numbers, it is evident that girls were significantly more active in domestic work of all kinds, especially emotional caretaking work.

Table 1 - Total Number of Interview Participants Who Had Experienced Recent Parental Deployments; Extra Domestic and Care Work Carried Out by Gender

\begin{tabular}{|l|c|c|c|c|c|}
\cline { 2 - 6 } & $\begin{array}{c}\text { Total } \\
\text { Participants } \\
\text { Who Had } \\
\text { Experienced } \\
\text { Recent Parental } \\
\text { Deployments }\end{array}$ & $\begin{array}{c}\text { Total Number } \\
\text { from Column 1 } \\
\text { Who Reported } \\
\text { Caring for } \\
\text { Siblings }\end{array}$ & $\begin{array}{c}\text { Total Number } \\
\text { from Column } \\
\text { 1 Who } \\
\text { Reported } \\
\text { Doing Extra } \\
\text { Chores }\end{array}$ & $\begin{array}{c}\text { Total Number } \\
\text { from Column 1 } \\
\text { Who Reported } \\
\text { Doing } \\
\text { Emotional } \\
\text { Work } \\
\text { (e.g., preventing } \\
\text { fights, supporting } \\
\text { parent) }\end{array}$ & $\begin{array}{c}\text { Total Number } \\
\text { from Column } \\
\text { 1 Who } \\
\text { Reported } \\
\text { Doing } \\
\text { Little or } \\
\text { Nothing } \\
\text { During the } \\
\text { Deployment }\end{array}$ \\
\hline Boys & 18 & 3 & 8 & 2 & 2 \\
\hline Girls & 24 & 10 & 13 & 10 & 1 \\
\hline
\end{tabular}

Boys reported mainly instrumental chores, such as shovelling snow or hauling in firewood.

For example, Harold, ${ }^{5}$ a junior boy, stated that his household "didn't change much" when his father was away, and described his own household work during deployments as

Basically, anything he would normally do, like ... haul in the firewood. Anything that needs to get fixed or something that has to be dealt with, I kind of have to deal with it whenever he's not there, or figure out how to deal with it, or call him and ask him how to do it.

\footnotetext{
${ }^{5}$ All names used are pseudonyms.
} 
Pete, a senior boy, told us, similarly:

I usually just vacuumed and tidied up a little bit, like put cushions over this way or something. Just cleaned up the floor area, and that was probably it.

A couple of boys actually created extra work for their mothers during a deployment by taking advantage of the fact that the family disciplinarian was absent. Speaking of his father's deployment to Afghanistan, one such senior boy (Roger) confessed:

We became pretty rebellious towards her, using a lot of profanity at her and stuff like that. Because me and my brother, we think we're above our mom when my dad's not home.

Girls, in contrast, described their chores and emotional work in detail. For example, Marlene, a senior girl, described her daily life when she was 12, providing most of the care for her two younger sisters when their mother was away on basic training.

I was the mother role now, 'cause my dad was working. So I got up early in the morning,... got my sisters ready to catch the bus, ... made lunches and ... got myself ready for school. And then, I would come home after school and ... I had to make dinner and make sure the girls did their homework. ... [When] my dad got home, I'd have dinner on the table.

Describing a typical day during her father's recent deployment to Afghanistan while her mother worked long shifts at a job away from home, Rosanna, another senior girl, itemized:

School, then come home and make supper for my sister. And then I'd have to get a ride to cheerleading and come home and put her to bed, and then do laundry and dishes.

She added:

I stayed home with my sister probably three weekends out of a month.

On the emotional side, Heather, a junior girl, described how she had reorganized her social life in order to prioritize her mother's social needs while her father was away on an unaccompanied posting.

I don't like going out with my friends, so I usually bring my friends over. 'Cause I don't like leaving my mom home... She says it's fine when I go out, but I think she'd be bored. ... She has friends, but she doesn't go out much. 
Louanne, another junior girl, described how she acted as confidante for her mother during her father's (then current) deployment to Afghanistan:

She's going through a lot right now with my dad being gone and her mom [has a serious illness]. ... And things are going wrong at work, and she has all this stress, and she doesn't really have anyone to talk to about it. So I sit there and talk to her about her problems ...

Jasmine, a senior girl, reported taking responsibility for the anxiety her mother experienced when her father was in Afghanistan, to the extent of berating herself for "burdening" her mother with her own fears.

Now that I look back on it, I wish that I hadn't of told her that it scared me. ... Because I found that I was the one person she could talk to, really, and trust. Because I never talked about stuff that we talked about with anybody else. ... I kind of wish that I didn't tell her that I was scared because then she wouldn't have felt stuck, that she didn't have anybody else to talk to.

Girls also provided emotional care to their siblings. For example, Rosanna (introduced above) described how she calmed her sister down the day the latter found out that their father's location in Afghanistan was more dangerous than they had originally been told.

She was really mad because my dad was lying to her. And then I had to comfort her. And I stayed with her and I told her that he was safe. That she shouldn't worry, because it'll be okay.

Sarah, another senior girl, who was tasked with most of the care for her younger brother during her father's recent deployment, took pride in how she had become much more adept at "handling" him than her mother.

He listens to me more than he listens to Mom. Like if I tell him to do something, there's a very good chance he'll do it. Whereas if Mom tells him, he'll just sit there and look at her like, "I'm not going to listen to you." ... Because ... I'll make him do it.

Girls' emotional work during deployments also included developing expertise in family communication, keeping family members from fighting, and refereeing fights that occurred. For example, Jasmine described the intricate way in which she filtered communication received from her 
father while he was in Afghanistan, in order to protect her younger brother from aspects of the message which might have upset him.

It's sort of like the chain of command in my family. My dad will tell my mom, Mom will tell me, and I'll tell my brother. That was usually how it worked, because a lot of times my father ... just kind of mentioned it off to the side. And then Mom would vent [to me] about her problems, or [about] whatever Dad [had] said. If it was something important then, sure, I would tell my brother. But ... if it was not important and it might threaten hurting him in some way, then I wouldn't. "It's okay, he doesn't need to know about that." So I was kind of like the filter.

Betty, another senior girl, described the role she carved out for herself while her mother was on basic training, keeping family relationships in harmony.

I felt there was pressure. ... When my brother and my dad got into an argument, I felt I had to resolve it to keep them not fighting. I don't know why I felt that way, just felt like I needed to do something to make everyone get along.

Girls' emotional work additionally included self-censorship: that is, protecting both their deployed and undeployed parents from additional stress by refraining from sharing potentially upsetting personal problems with either of them. For example, Jasmine described how she, her mother, and siblings communicated with her father when he was in Afghanistan.

When my dad called, we talked to him and we'd tell him everything good that was going on. We'd never tell him anything bad, because that's the last thing you want them thinking about. ... Like, he was just a couple hours away is the way that we made it sound when we were talking.

Chantal, a senior girl with a frequently deployed father and chronically ill mother, did not tell her parents for four years about the severe bullying she had been subjected to at elementary school.

Because I didn't want to make matters worse, I just kept it to myself. ... I actually didn't tell them till about Grade 9 ... four years after I moved down here.

A few of the adolescent boys we interviewed were atypical in that they provided emotional support to their mothers when their fathers were deployed. For example, Patrick, a senior boy whose father spent nine months in Afghanistan, recalled how he helped his mother bring the Easter Bunny 
to his younger siblings while his father was away, right after learning of several Armyville Afghanistan casualties.

And of course it being Easter weekend, the Easter Bunny still had to come. And so that was kind of the first time that I helped Mom with that, but she really needed help. I mean, before that I believed in the Easter Bunny. ... I didn't really care that he wasn't real any more. It was more my mom needed me.

Another senior boy, Mark, described suppressing his own needs during his father's deployments, to ease the burden for his mother, who is chronically depressed.

Having my dad go away constantly, Mom being depressed... It's almost like you're living with yourself. Because you don't want to talk to your mom about it because she's depressed, and you don't want to make her more depressed, and you don't want to make her think about it. And then you're sitting there like, "What am I going to do?" and you have to come up with your own reasons, your own answers.

In general, however, the adolescent boys we interviewed appeared to provide significantly less instrumental and emotional support to their families when their parents were deployed. As we saw above, a few even took advantage of, or benefited from, the CF parent's absence. This gender difference in our findings likely reflects traditional expectations about the gendered division of labour in the home (Armstrong and Armstrong, 1990; Kwan-Lafond et al., 2011).

\section{(b) Parentification and the Adolescent's Relationship with His/Her Undeployed Parent}

The essence of parentification is that the child or adolescent assumes adult roles in the household, to compensate for the fact that, for whatever reason, his/her parent(s) is/are "unavailable." Parental emotional unavailability appears to be an especially significant aspect of the daily life of the child or adolescent with a father or mother deployed. The deployed parent is unavailable because s/he is deployed and, as noted above, communication with this parent is normally expected to be superficial and cheerful, to enable him/her to stay focused on his/her mission, without being distracted by domestic problems (Harrison \& Laliberte, 1994). The parent remaining at home is frequently also 
emotionally unavailable, owing to his/her fulltime work commitments, temporary new status as a solo parent, and/or anxious state of mind brought on by the other parent's deployment.

Emotional unavailability of the undeployed parent was a frequent theme in our interviews. For example, when asked to describe a typical "bad" day during his father's deployment, Oliver, a junior boy with a busy working mother, replied:

You're really missing [your dad]. And then you go to school and nothing's really working out for you. ... And then you go home and your mom has to work late, and you have to get yourself a sandwich for supper.

Justin, another junior boy, described the stress and anger continually expressed by his mother during his father's deployments.

She's very stressed out. ... She just usually gets noticeably angrier. ... Like if I had small problems, she'd flip. And every day after work, she's just so angry and stressed out that she won't talk. ... I can't really find a word to describe [how horrible it is]. Just constantly tension everywhere.

Marlene (introduced earlier), whose mother spent almost a year on basic training, lived with a father who was unable to provide any nurturing to his children. She described her daily life as:

It was pretty much leave for work, come back for dinner, go to bed, leave for work, come back for dinner. That was it. We didn't really talk. It was just "Here's your dinner. I'm going to go watch TV now." ... That was it. I didn't talk to anybody. .. I was really, really lonely.

Sarah (introduced earlier) reported staying away from home during her father's second long overseas deployment, in order to avoid interacting with her mother.

That was hard, because me and my dad get along. And me and my mom, we have a lot harder time of getting along. We fight more. So the first time, it was really really hard. And the second time, I wasn't home. I'd go to friends' houses, so I didn't have to deal with my mom and my brother.

All of these participants (especially Marlene and Sarah, who had been carrying out parental roles) endured more difficult deployments than necessary, as a result of receiving too little nurturing from their parents who had stayed home. 
Parental unavailability can sometimes become permanent. For example, Rosanna (introduced earlier) believes that the stress created by the fact that her father is frequently away on a tour has caused her mother to become permanently lost to her. When asked "Who is the mom for you?" she replied "Nobody really," elaborating

She tries to be there, but it's different. And now she's in school, so she's not here very much. She goes to school and then she has to pick up extra shifts, now that my dad is in Province X. ... She's always working. And now she's always at school and she's more stressed than she was before.

Marlene, whose two CF parents were sent on long deployments back-to-back, described how her self-censorship may have permanently eroded her ability to communicate with either of them.

We started getting really distant, and not telling him as much - and same with my mom. I didn't hide stuff from them. I just didn't tell them as much, so they could get back to being them again and not have to worry about me. ... It's really hard, 'cause my mom and dad are gone so much. Like, my mom's gone on course. My dad's gone on course. My dad's gone to Afghanistan. My dad's gone to Country X. ... It's never really stable.

Mark (introduced earlier), whose father was in Afghanistan and whose mother was chronically depressed, revealed his mother's permanent unavailability by expressing his extreme anxiety during the deployment at the prospect of the "only parent he could count on" not returning. He told us:

That was basically my only thought during the whole time. "I want him to come home, you better come home." Like, he's the only reason why our family stays together. .. [If he didn't come home] it would make things a lot more difficult.

In summary, parentification entailed intricate instrumental and emotional domestic work on the part of some of our research participants with deployed parents (especially the girls), in the frequent context of both parents being unavailable to them as sources of support. In retrospect, did the adolescents hold a positive view of their experience of having been subjected to these challenges? Or did they believe that the stresses they had endured outweighed any benefits they had received? Their answers, as we will see, were mixed. 


\section{(c) Consequences of Parentification}

Like the literature, our participants were divided - even within themselves - concerning the consequences of parentification for them. On the positive side, and consistent with the findings of

Mmari et al. (2009), Marlene expressed pride in her accomplishments:

I liked being in charge. ... I could tell my sisters to do stuff around the house. You know, "Can you please come and do the dishes? Can you please sweep the floors? Can you go tidy your rooms?" Stuff like that, and if they didn't then it was just my job, and I knew I had to do it. ... And I liked being home. I liked being with my sisters, and that was it.

Patrick, similarly, was proud of the closer relationship now existing between him and his mom, as a result of his father's deployment to Afghanistan.

Over the last few years, she's seen me grow into the boy or man that she didn't expect me to grow into at the time before Dad left for Afghanistan. We grew a lot closer. I mean we were close before Afghanistan, as a mother is to her oldest son. But not that close. She needed me a lot when Dad was gone.

Indeed, both these participants found the transition to no longer being in charge to be a difficult one when their deployed parents returned home. Marlene told us:

I liked having a lot of responsibility. I liked being in charge. And then I went back to not being in charge at all. So the transition was really difficult.... Because, you know, I would tell my sisters to do something, and Mom would be like "Marlene, don't say that." And I was like "Oh, right, I'm not in charge any more, I forgot." And me and my parents started fighting.

Patrick said, similarly:

I still boss my brothers around. And Dad has to remind me every once in a while, "I'm the man of the house now. If you guys have a problem, just come to me. Don't try and handle it yourself."

Nevertheless, along with the positive narratives cited above, some of our participants reinforced the findings of previous research by confirming that parental unavailability, as caused by parental deployments, had created significant emotional stress for them. For example, speaking of her father's deployment to Afghanistan several years ago, Rosanna told us:

I liked helping my mom. But the down part was ... not being a teenager. 
She added:

I have days where I break down and just want to cry all day. ... It's like a build-up, and then I just need to cry it out, and then I'm all good. Until something big happens, and then I need to talk to somebody. I don't usually talk about my feelings with people because ... I'm the one who listens to people's problems. So when I cry, it's my way of letting my stress out, instead of talking about it or getting mad.

Jasmine complained about the same deployment:

I was only 15-16. When you think about it, technically that's still a kid, right? I didn't ask for the responsibilities that I got. They are just kind of given to you and expected of you to step up to the plate, and that's what I did. So you see a lot of people going out on weekends, and that wasn't me. I was at home helping around the house and doing what I could to try to step up into the responsibilities and step into the shoes where feet were missing in. I was kind of taking Dad's role, because I was always the person who helped fixed the car, mow the lawn, all the stuff that usually they say guys do or the father does. ... That was my job. ... At 15-16, those are big shoes to fill.

Unlike the participants quoted above, Jasmine did not become happily used to being "in charge" when her father was away. Instead, she resented being expected to continue these responsibilities after he returned. She told us:

When he got back, I wasn't doing all the same stuff that I was doing before, but I was still expected to have that responsibility. I was still expected to step up to the plate as much as I was before. When I was ready to step back down and be a kid again.

Patrick, whose father had warned him that he might not return from Afghanistan, alluded to the resulting emotional stress he experienced while his father was away.

He told me it was going to be dangerous. He told me it was going to be the most dangerous thing he's had to do in his life. And he wanted to prepare me in case something did happen. ... Before he left, he pulled me aside and told me that I was supposed to be the man of the house now that he's gone. ... A few weeks before he left, that's when he told me. And those few weeks I thought "Yeah, this is so cool. I'm going to be the man of the house now, and I'm only 15," and all that. But when he actually left, it was one of the hardest things I had to do. ... I felt [the responsibility] every day that he was gone.

Related to the stress expressed by the above participants, Joanne, a senior girl whose mother was very strong and available during her father's long overseas deployment, expressed gratitude for the fact that she was not required to assume a quasi-parental role during this deployment. 
[Mom and Dad] obviously knew how each other were feeling, but they never put it on me, which is nice. I have friends whose moms are like their best friend. And the moms tell them everything, how they're feeling. And they come to school more stressed than they were before, because the parent's not acting like the parent. ... I can go to [my mom] for things. But she's still my mom and she would never put that on me. 'Cause they chose that life.

She believed that her self-esteem would have plummeted if her mother had, instead, abdicated her role as parent.

Obviously my self-esteem would go down if my mom cried to me at night, saying how much she missed my dad, or she would blame my dad and us for how she's feeling. ... And if you were [continually] told it was your fault, your self-esteem would go down.

It is likely that Joanne had derived these insights into the advantages of her own situation from listening to peers whose experiences with their parents had been less fortunate. The contrast between her experience, and that of some of our other participants, illustrates how the extent of parentification occurring in a given family during a deployment depends partly on the adequacy of the parenting carried out during the deployment by the undeployed parent.

From the small amount of data presented here, we are unable to claim that the impact of deployment-derived parentification experiences on adolescents in military families is more beneficial than harmful to the adolescents' health and wellbeing - or the reverse. Certainly our participants were proud of their domestic achievements during parental deployments. On the other hand, developing adolescents need to spend quality time with their peers, pursue extracurricular activities, establish their first romantic relationships, and be mentored through new challenges by their parents. For a significant number of our participants, too few of these needs appeared to be being met during the parental deployments they discussed with us. In the next section, we will explore some links between our participants' parentification experiences and their respective expectations of support from their school. 


\section{(d) Parentification and Perception of School Support}

In the experience of the school personnel cited in Chandra et al.'s (2010) study, students with deployed parents were relying heavily on their schools for support, because both their parents were unavailable to them. Chandra et al.'s findings therefore suggest that schools have the potential to provide significant nurturing to students from military families during deployments. We asked our interview participants to comment on the quality of support provided to AHS students during deployments, by the school and also by individual teachers. Their opinions varied significantly.

For the most part, interestingly, it was participants whose parents had not experienced a recent deployment who made the most positive comments about the school's support for students with deployed parents. For example, Yvonne, a junior girl, said:

The guidance counsellors are really helpful with a lot of things. I know I've gone to the guidance counsellors for things before, and they always try. They may not always know how to help you exactly, but they try their best.

Howard, a junior boy, added:

The guidance program is supposed to be really good, apparently. I never went there so I wouldn't know, but I heard it's pretty good. There's always someone to talk to.

Both of the above positive comments were vague in nature. In contrast, most comments about school support from the offspring of recently deployed parents were quite specific/targeted in their focus, as well as being somewhat negative. For example, Jonathan, a senior boy, believed that the school had responded in a "too little too late" fashion to the recent Afghanistan deployment of his father and a number of other parents.

They never really drew attention to it. It's kind of something they didn't make public. The only time they really did anything was when they decided to have a thing where all kids could go who had their parents deployed. ... By that time, you were used to not having support from [them]. 
He added that the school had publicized the Afghanistan deployment in such an upbeat fashion that civilian students were not mobilized, as they might have been, to offer support to their affected peers.

The school is kind of sugar-coating it... saying it's nothing too bad. Like [the civilian students] didn't quite understand what's going on there.

Sarah (introduced earlier), whose father was frequently deployed (although not to Afghanistan), believed that the school took too little initiative in offering support to students with deployed parents. The guidance office was apparently not equipped to provide counselling on the spur of the moment (it insisted that students make an appointment), and its personnel seemed to fail to understand that students with deployed parents were often "hurting" too much to be organized enough to schedule their requests for support in advance. Sarah said:

The guidance counsellors were always there, but they never took the initiative to realize like "Oh, you're in the military." They just kind of said, "Well, if you need us we're here to talk." ... Most of the time you can't just show up and be like, "Well, I feel like I just want to talk." Because they'd be like, "Oh, you can go make an appointment then." Like, I'm going to make an appointment to talk to you about what I'm feeling right now? I don't think so.

Joanne (also introduced earlier) believed that school personnel were often unable to help students whose parents were deployed because they didn't know who these students were.

It's not their fault, but they don't know anything. ... They [should] have at least a list... and bring it to the military, and say like, "Please tell me who are deployed right now." And get all those kids into a room. And I'll bet you they'll all be sobbing within 15 minutes of asking them questions, because they have it all bottled up inside of them.

She added that, partly because of this lack of information, teachers found it difficult to understand that a student who acted out during an Afghanistan deployment was doing so because s/he was missing and/or worried about a parent who was there.

If a kid is really obnoxious in class, or rude in class, there's obviously something behind it. There's some motive of why they may be acting out. Some teachers find it over and above their job to address it. Over and above like, "Oh, they're just a troubled child." Like, get them through this class with a 60, and then they'll be off to the next teacher. 
She added:

I know a lot of them are just acting out to act out. But some of them are probably acting out because they have problems at home because one of their parents are being deployed, or one of their parents are going through things in the military.

Jasmine believed that the teachers lacked the training they would have needed to enable them to work effectively with students who had deployed parents.

Teachers are supposedly trained about how to deal with kids whose parents have gone to Afghanistan. You need more training than that. You can't just have a three-hour lecture on what to expect, and then consider yourself qualified to deal with that kind of thing. ... A lot of the times, my mom actually ended up calling the school and explaining what was going on. ... They weren't understanding. They just saw [my brother] as a troublesome boy, a typical boy who was causing disturbances in class.

She added:

That was one of the big things to expect was that there was going to be changes in learning, or your grades may slip, or recognize the signs of something bothering you, the stress of your loved one gone over there. They didn't recognize it. They were told about it, but they never recognized it.

Jasmine also lacked confidence in the preparedness of the school's guidance counsellors.

Counsellors, they think that they can help you deal with it, but not the same that you're looking for. Like the help you're looking for, you want somebody with experience and who knows how to deal with it. ... I didn't trust the counsellors at school. ... Usually, it takes me ... time to get to know somebody, to kind of let this kind of thing out. I never got to know any of them, and just by kind of like first impressions and meeting them a couple of times, I wouldn't trust them as far as I could throw them.

As corroboration of these opinions, Roger (introduced earlier), who had been severely disciplined for "acting out" while his father was in Afghanistan, believed that the root of the problem had been a complete breakdown in communication between himself and school personnel.

I didn't really express myself too much that my dad was gone. They knew that something was wrong when I started cutting school. Because first term was okay, second term I cut school.

In summary, despite having taken admirable steps to respond in a proactive manner to the Canadian Forces' new ongoing combat deployments to Afghanistan, it would appear from our interview data that, as of 2009/10, AHS may have been responding insufficiently to meet the needs 
of the students who were most affected by these deployments - at least in the minds of some of these students. This is not surprising, since wartime was as unfamiliar a situation at that time to all schools in communities near Canadian military bases (including AHS) as it was to the Canadian Forces. Furthermore, a major factor affecting school personnel's failure to accurately interpret the behavioural cues of their troubled students would almost certainly have been (as Joanne noted) the school's lack of information regarding which of these students' parents were actually deployed.

Our data suggest that the real or perceived deficiencies in the school's support system had been observed more intensively by CF students who had lived through recent overseas deployments than by their peers who had not. This would be a plausible interpretation, in view of the fact that students who had experienced difficult deployments, especially those who had been parentified, would have been those who had been most in need of support from the school, and consequently also most conscious of the kinds of school support that might have been missing. To take these speculations one step further, it would be plausible to hypothesize that military adolescents require support from their schools during parental deployments to the extent that they have been parentified at home.

\section{Conclusion}

Most of the literature on childhood parentification has been psychological, and has focused on the negative effects of parentification on children. Few studies have attempted to make sense of the divergent social contexts of parentification, and fewer still have focused on the parentification of adolescents in military families. This paper has used recent stressful overseas parental military deployments as the backdrop for an exploration of parentification. We found that the parentification experiences of our interview participants (1) varied by gender, (2) varied by the quality of their 
relationships with their undeployed parents, and (3) exercised an influence on how acutely they perceived deficiencies in the support offered by their high school.

We found parentification to be much more strongly at work in the experiences of the adolescent girls we interviewed about parental deployments than in the experiences of their male peers. Especially notable were Marlene, who looked after her entire household at the age of 12; Heather, who integrated her lonely mother into her own adolescent social life; Louanne and Jasmine, who provided significant emotional support to their mothers - Jasmine to the extent of suppressing (or wishing that she had suppressed) her own fears about her father's deployment; Sarah, whose mother had entrusted her with most of the care of her younger brother; and Jasmine and Chantal, who protected both their parents by keeping silent about their own problems.

We also found that interview participants who had experienced a recent parental deployment were both more negative and more specific in their feedback about the quality of deployment support provided by teachers and guidance counsellors at the school. For example, Jonathan referred to the school's "sugar coating" of the war in Afghanistan; Sarah criticized the guidance office's refusal to provide support without an appointment; Joanne mentioned teachers' ignorance regarding which students' parents were deployed, and of how an adolescent's acting out during a deployment might reflect the stress his/her family was experiencing; and Jasmine highlighted the deploymentrelated training that she believed school personnel had failed to receive.

We need to take seriously the gratitude that some of these youth expressed for the responsibilities they had been forced to assume. However, some of the emotional unavailability of their undeployed parents seemed to have created significant stress for them. We recall in particular the angry and tense home atmosphere created by Justin's mother; the nurturing that was absent in the parenting provided by Marlene's father and Sarah's mother; and how Mark, whose mother was depressed, believed that he had lost the only parent he could count on, and feared the future in the 
event of his deployed father never coming home. Rosanna, Jasmine, and Patrick expressed awareness of the emotional costs to them of the ways in which they had been parentified while their fathers were away; relatedly, Joanne expressed relief that parentification had not happened to her. While we are unable to form conclusions about the long-term consequences of parental deployments for these young people, our interviews suggest that, in the short and medium term, the quality of the relationship with the undeployed parent is a crucial factor.

The implications of our findings are twofold. First, in keeping with traditional expectations about domestic labour and gender, deployments appear to demand more from the daughters of deployed members than they demand from sons. This statement should not be interpreted as an attempt to minimize the work and suffering that male adolescents put into their parents' deployments. Indeed, a strong need exists for community organizations which provide support to children of deployed military members to develop effective strategies to assist adolescents of both genders. However, our findings suggest that girls could especially benefit from curriculum modules which focused on the costs to women of gender role socialization and the gender division of labour, and from support initiatives that were predicated on a realistic assessment of how gender socialization is likely to occur within communities located near army bases.

Second, between the lines of their comments, our interview participants appeared to express the need for more knowledgeable and proactive support to be provided by schools to adolescents who are affected by parental military deployments. Enhanced school support could potentially fill some of the vacuums created by the parental emotional unavailability that is the unavoidable byproduct of the situation of adults who are responding as heroically as they can to the overwhelming stresses that deployments create. Enhanced school support could also ease some of the burdens that many undeployed parents now shoulder alone. Education is a provincial responsibility in Canada. However, since decisions to participate in overseas missions are made at the federal level, it would 
be appropriate for the federal government to assume responsibility for assisting provinces to enable schools located near military bases to increase their levels of support to students whose parents have been deployed. ${ }^{6}$

Our exploratory research adds to, and is consistent with, the small body of previous qualitative research on adolescents who can be described as parentified during the deployments of their military parents (Huebner et al., 2007; Mmari et al., 2009; Chandra et al., 2010). Our findings would have been richer, however, if we had carried out interviews on these topics with the adolescents' civilian parents, and with AHS school personnel, as well as interviewing the adolescents themselves. Additionally, the adolescents who agreed to be interviewed by us were, as noted above, self-selected, and not necessarily representative of all the CF adolescents at AHS. We likely did not hear from some of the adolescents who felt most vulnerable around the issues that were discussed in the interviews.

The small amount of research that has been conducted on adult children of military members who suffered PTSD during the children's childhoods has been very useful (e.g., Rosenheck, 1986; Suozzi and Motta, 2004). Especially the adult children of World War II veterans interviewed by Rosenheck demonstrated noteworthy retrospective insight into the impact of this childhood experience on their adult lives and life choices. In order to assess the long-term impacts of parentification experiences during deployments, it will be similarly important for us to conduct retrospective research with the affected adolescents 10 and 20 years later. Our most urgent presentday research need, however, is additional studies of adolescents' family experiences during post9/11 wartime deployments.

\footnotetext{
${ }^{6}$ At the present time, the province in which Armyville is situated provides only one guidance counsellor for every 520 students enrolled at each secondary school. (Personal communication from a District Superintendent)
} 
Harrison and Albanese

\section{References}

Andres, M., \& Moelker, R. (2011). There and back again: How parental experiences affect children's adjustments in the course of military deployments. Armed Forces \& Society, 37 (3), 418-447.

Armstrong, P., \& Armstrong, H. (1990). Theorizing women's work. Toronto: Garamond.

Barnett, B., \& Parker, G. (1998). The parentified child: Early competence or childhood deprivation? Child \& Adolescent Mental Health, 3 (4), 146-155.

Broszormenyi-Nagy, I., \& Spark, G. (1973). Invisible loyalties: Reciprocity in intergenerational family therapy. Hagerstown, MD: Harper \& Row.

Chandra, A., Martin, L.T., Hawkins, S.A., \& Richardson, A. (2010). The impact of parental deployment on child social and emotional functioning: Perspectives of school staff. Journal of Adolescent Health, 146 (3), 218-223.

Charmaz, K. (2004). Grounded theory. In S.N. Hesse-Biber \& P. Leavy (Eds.), Approaches to qualitative research (pp. 496-521). New York: Oxford University Press.

Department of National Defence Canada. (2000). Building on a stronger foundation: Annual Report of the Chief of the Defence Staff 1999-2000. Ottawa: Department of National Defence.

Earley, L., \& Cushway, D. J. (2002). The parentified child. Clinical Child Psychology \& Psychiatry, 7 (2), 163-178.

Fitzgerald, M., Salstrom, S., Jackson, J., Schneider, R., Zinzow, H., \& Fossel, R. (2008). Child sexual abuse, early family risk, and childhood parentification: Pathways to current psychosocial adjustment. Journal of Family Psychology, 22 (2), 320-324.

Harrison, D., \& Laliberté, L. (1994). No life like it: Military wives in Canada. Toronto: James Lorimer \& Company.

Hooper, L. (2007). Expanding the discussion regarding parentification and its varied outcomes: Implications for mental health research and practice. Journal of Mental Health Counseling, 29 (4), 322-337.

Huebner, A.J., Mancini, J.A., Wilcox, R.M., Grass, S.R., \& Grass, G.A. (2007). Parental deployment and youth in military families: Exploring uncertainty and ambiguous loss. Family Relations, $56,112-122$.

Kelley, M.L. (1994). The effects of military-induced separation on family factors and child behavior. American Journal of Orthopsychiatry, 64 (1), 103-111. 
Kelley, M., French, A., Bountress, K., Keefe, H., Schroeder, V., Steer, K., Fals-Stewart, W., \& Gumienny, L. (2007). Parentification and family responsibility in the family of origin of adult children of alcoholics. Addictive Behaviors, 32 (4), 675-685.

Kwan-Lafond, D., Harrison, D., \& Albanese, P. (2011). Parental military deployments and adolescents' household work. Studies in Political Economy, 88 (Fall), 161-188.

Mayseless, O., \& Scharf, M. (2009). Too close for comfort: Inadequate boundaries with parents and individuation in late adolescent girls. American Journal of Orthopsychiatry, 79 (2), 191-202.

Medway, F.J., Davis, K.E., Cafferty, T.P., Chappell, K.D., \& O’Hearn, R.E. (1995). Family disruption and adult attachment correlates of spouse and child reactions to separation and reunion due to Operation Desert Storm. Journal of Social and Clinical Psychology, 14 (2), 97-118.

Minuchin, S., Montalvo, B., Guerney, B., Rosman, B., \& Schumer, F. (1967). Families of the slums. New York: Basic Books.

Mmari, K., Roche, K., Sudhinaraset, M., \& Blum, R. (2009). When a parent goes off to war: Exploring the issues faced by adolescents and their families. Youth \& Society, 40 (4), $455-$ 475.

Rosenheck, R. (1986). Impact of posttraumatic stress disorder of World War II on the next generation. Journal of Nervous and Mental Disease, 174 (6), 319-327.

Statistics Canada (1997). National longitudinal survey of children and youth 1994-1995: Public use microdata files user's documentation. Ottawa: Author.

Strauss, A., \& Corbin, J. (1990). Basics of qualitative research: Grounded theory procedures and techniques. Newbury Park: Sage Publications.

Suozzi, J.M., \& Motta, R.W. (2004). The relationship between combat exposure and the transfer of trauma-like symptoms to offspring of veterans. Traumatology, 10, 17-37.

Treasury Board of Canada. (2007). Expenditure review of federal public sector - Volume Two: Compensation snapshot and historical perspective, 1990 to 2003. Ottawa.

Ungar, M., Theron, L., \& Didkowsky, N. (2011). Adolescents' precocious and developmentally appropriate contributions to their families' well-being and resilience in five countries. Family Relations, 60 (2), 231-246.

Wertsch, M.E. (1991). Military brats: Legacies of childhood inside the fortress. New York: Random House.

Woolgar, M., \& Murray, L. (2010). The representation of fathers by children of depressed mothers: Refining the meaning of parentification in high-risk samples. Journal of Child Psychology \& Psychiatry, 51(5), 621-629. 